\title{
Kurdish EFL Learners' Spelling Error Types and Sources
}

\author{
Jamal Ali Omar \\ Department of English Language, University of Raparin \\ jamal.ali@uor.edu.krd
}

\begin{abstract}
:
The current study investigates the types and sources of spelling errors of Kurdish ${ }^{1}$ EFL learners. To this end, 82 argumentative articles written by senior university-level students were analyzed to identify the spelling errors. The process of classification and identification of the error type in the research was based on Cook's (1997) familiar categories of errors. The results obtained showed that the type of errors were omission, insertion, substitution, transposition, space accuracy and capitalization. Those errors were originated from various sources among which instructional, overgeneralization and pure were prominent. It was also concluded that letter/sound correspondence creates problem for the learners. Interpretation of the results implies that pedagogical decision and further research is required in the learning context of Kurdish EFL learners.
\end{abstract}

Keywords: Types of Spelling Errors, Kurdish EFL learners, Omission, Insertion, Transposition and Substitution Errors. 


\section{Introduction}

As one of the challenging skill of language learning, EFL learners face difficulties to gain the writing skill. This is so because acquiring the skill entails learning about the writing system, orthography, spelling and punctuation. Hence, in the course of acquiring writing skill, various types of errors occur in EFL learners. These include grammatical, word choice organizational and spelling errors. The latter type, particularly, as they are common in writing of not only EFL learners but English native speakers as well, will negatively affect the written performance of EFL learners. Spelling errors affect not only the written performance, they might have other consequences. Reference [7] stated that "Spelling is thus a crucial factor in the way people present themselves". Recently, Reference [6] stated that "A spelling mistake is as important as a pronunciation mistake, indeed more so in that bad spelling carries overtones of illiteracy and stupidity which bad pronunciation does not" (p. 111). Thus, the study of EFL learners' spelling errors is invaluable to classify the error types on one hand, and identifying the source of the errors type on the other. The pedagogical impetus is to find solution that will help minimizing the error rate in the learners' L2 writing.

The present paper attempts to study the area, with particular focus on Kurdish EFL learners, aiming at tackling the problem and recommending suitable remedial solution. To this end, the area's research background and literature review are presented in the next section below.

\section{Background and Literature Review}

Writing generally requires one to acquire knowledge of writing system, orthography, organization, spelling and punctuation even when writing in the first language. Writing in L2, however, besides acquiring the above elements of L2 writing knowledge, may be influenced by L1 writing knowledge, lack of L2 writing knowledge, L2 instructional knowledge and L2 writing complexities. In the course of acquiring L2 writing knowledge, learners are liable to make various types of errors among which spelling are common in EFL learners. Based on the works done in the area, it is confirmed that the errors have different types and sources among which interlingual, intralingual and unique types are prominent [9]. Also, there are other types such as insertion, substitution, omission, transformation and transposition [7] which are to be considered the most significant classification of error types. Other recent types of spelling errors include space inaccuracy, capitalization, inflectional endings and learner-specific types ([2], [1], [5], [9], [10] among others). With regard to the sources or causes of the errors, many studies were also carried 
out by which various results have been obtained. The results showed that the source of the error was L2 (intralingual), L1 (interlingual) or unique the learners of various L1 background. For example, in case of errors for which L2 was the source, there are some reasons such as letters written in English orthography but not pronounced, acoustically similar-sounding words and homophones in L2 and a letter in English orthography is pronounced differently in different words [9]. However, in case of errors for which L1 was the source, there are some reasons such as phonemes absent in L1 or represented differently from L2, the absence of phonemic distinction for a single sound in L1 and articulatory differences in producing some phonemes in L1 and L2 [9]. The type of spelling inaccuracies and the causes of misspelling of EFL learners were also investigated and examined by making language proficiency learners and various L1 background the independent variables. The empirical studies carried out had come out with results by which common causes were identified. The causes were summarized as the difference between the writing systems of the source and recipient languages, lack of adequate knowledge of L2 phonology and insufficient knowledge of the inflectional morphology, the mismatch found between the letters and sounds of English language (irregularity of English orthographic system), mother tongue influence, etc. Some of the empirical studies are presented below. Reference [1] carried out a study to find out the type of error in high school Kurdish EFL learners' writing. The focus of the study was on the mechanics of writing in which the percentage of the frequency of writing error in spelling, punctuation, capitalization, contraction, etc. was calculated by male and female Kurdish writers. The results showed that, without referring to the type of spelling errors, spelling, contractions and capitalization had reasonable share of errors in the mechanics of writing between the two groups. Reference [2] recently investigated the type source of junior Kurdish EFL university students. He analyzed 40 compositions written the learners to identify the spelling errors. The results showed that eight categories of English spelling mistakes were identified; Insertion, omission, substitutions, transposition, grapheme substitution, space inaccuracy, capitalization and others. Interpretation of the results revealed that the potential causes of the errors were lack of sufficient phonological and morphological knowledge of English language and the dissimilarity between English and Kurdish writing systems tend to be the main causes. Reference [8] conducted a study to find out the spelling errors among Arabs and non-Arab ESL students. The results revealed that Arab students spelling skills were not enough to tackle spelling difficulties in general and multi-syllabic words in particular. Reference [3], in their turn, examined the composition spelling errors of 43 EFL undergraduate Jordanian students. The results showed that there were 228 errors which were obtained from analyzing 43 written papers, and they were categorized into four types according to Cook's classification (1997): omission, substitution, insertion, and transposition. The findings also revealed that the majority of students 
committed substitution and omission spelling errors. Reference [10] conducted a study on Iraqi students, who are studying English language as an essential requirement to begin their academic study in Malaysian universities to investigate the spelling mistakes and errors. They used a questionnaire and a writing task to collect data. The results revealed the total of 344 errors distributed, sequentially from the highest to the lowest, among the four types of omission, insertion, substitution and transposition. The results also indicated that the cause of the errors were the difference between the spoken and written language, the origin of the English words and students' carelessness. Reference [4] conducted a study on Saudi 122 EFL undergraduate students at the University of Ha'il to examine the types of spelling errors in English composition. The findings indicated that omission errors were considered the highest among students. The findings also revealed that spelling errors occur as a result of anomalies existing in L2 as well as L1 interference. Finally, Reference [9] examined the source of spelling errors of 51 high school Iranian EFL learners by analyzing their dictation samples. The results showed three sources of errors as intralingual, interlingual and unique types among which intralingual errors outnumbered the other types. The results also indicated seven patterns of errors.

To conclude, despite the importance of correct spelling for written production, the dearth of research on spelling problems in Kurdish EFL learners' context exists due to insufficient attention paid to writing skill of language learning in general and spelling errors in particular. Moreover, knowing about the type and understanding the sources of errors Kurdish EFL learners may have been limited to the difference between the orthographic systems, however, there may be other causes for spelling errors. The present study is intended to fill in this gap and offer suggestions and recommendations by which the Kurdish English learners' spelling proficiency is hopefully improved.

\section{Methodology}

To achieve the stated aim, 82 argumentative articles written by Kurdish EFL university students majoring in English language were analyzed. The participants were senior university students of English department from three public universities of University of Raparin, Koya University and University of Sulaymaniyah in Kurdistan Region in north of Iraq. They were voluntarily took part in the study. The average of their age is 22 years. Data collection started by making the participants write the article in response to the prompt "Some people believe that when parents make their children's lives too easy, they can actually harm their children instead" within a time limit of 40 minutes. It is worthwhile that the data was earlier used in a $\mathrm{PhD}$ thesis written by the researcher, but the focus was on the patterns of discourse 
organization. In the procedure of data analysis, we used a check list by which the type of errors were identified in those articles. The process was to classify the errors based on the types earlier identified in the literature by Cook (1997) as well as errors unique to Kurdish EFL learners. The focus of the analysis was on the number and type of error made by those learners. Hence, the primary aim of the present paper is descriptive: what types of errors do Kurdish L2 users of English make? Then, interpreting the results will indicate the cause of the error types.

\section{Results}

The results showed identification of various types of spelling errors with diverse rates. The number of the errors was around 270 which divided upon omission, substitution, transposition, insertion (addition), space accuracy, capitalization and unique types of errors. The table below shows the number and types of errors occurred in Kurdish EFL learners:

Table 1. Kurdish EFL Learners' Number and Type of Spelling Errors.

\begin{tabular}{ccccccc}
\hline Omission & Substitution & Insertion & Space & Capitalization & Transposition & Unique \\
\hline 78 & 30 & 42 & 48 & 20 & 17 & 32 \\
\hline
\end{tabular}

Total $=267$

It is clear that the largest number of spelling errors was omission, space accuracy and insertion. However, the smallest number of spelling errors transposition, capitalization, substitution and unique types of errors. Details and examples of the error types are presented below.

\section{A. Omissions}

Omission is one of the most common spelling errors in EFL learners. The most commonly omitted letters in Kurdish EFL texts were $\langle\mathrm{e}\rangle,\langle\mathrm{l}\rangle$ and $\langle\mathrm{u}\rangle$. First, the final silent $\langle\mathrm{e}\rangle$ was dropped by learners; phon (phone), mak (made), provid (provide), languag (language), lif (life), etc. Also, omission of <e> before <-ly> was common; lonly (lonely), definitly (definitely). Secondly, another largely omitted letter was $<1>$ particularly where this consonant was doubled; specialy (specially), fulifild (fulfilled), finaly (finally), psychologicaly (psychologically). It is worthwhile that double consonants were one of the common area in which omission of different letters occurred; apreciate (appreciate), exagerate (exaggerate), leting (letting), expres (express), enginer (engineer), suround (surround). Finally, the letter $<\mathrm{u}\rangle$ was also dropped by learners especially when it followed $\langle\mathrm{ou}\rangle$; shold (should), encorage (encourage), 
backgrond (background). Other common spelling inaccuracy was found in omitting the apostrophe of some contracting forms; cant (can't), childrens (children's), parent's (parents), dont (don't). In addition to the above common misspellings, other less common spelling errors were identified in the learners' texts. For example, omission of the letters $\langle\mathrm{i}\rangle,\langle\mathrm{y}\rangle,\langle\mathrm{n}\rangle,\langle\mathrm{r}\rangle,\langle\mathrm{p}\rangle,\langle\mathrm{s}\rangle,\langle\mathrm{t}\rangle$ and $\langle\mathrm{a}\rangle$ in the following words respectively; behaive (behave), studing (studying), istead (instead), lean (learn), attemts (attempts), nowaday (nowadays), righ (right) and vlue (value).

\section{B. Insertions}

Insertions found in the texts investigated were reflected in adding silent <e > mistakenly to the words Marke (mark), girle (girl), symbole (symbol), theme(3) (them), nervouse (nervous), depende (depend) focuse (focus). The letter <e> was also added systematically to nouns to make them plural; parentes (parents), giftes (gifts), problemes (problems). Another source of insertion was found in the consonant doubling, particularly in the mid and final positions; bonnd (bond), parrents (parents), allways (always), off course (of course), mercefull (merciful). Other insertion types caused by different reasons such as breaking apart consonant clusters as in childeren (children)(8), word form derivation as in electronical (electronic), cleaver (clever), realy, relay (rely) and healthy (health), and contraction as in cann't (can't) (4).

\section{Substitutions}

One of the major categories of errors for L2 users was substitution, replacing one letter with another single letter. Starting with vowel substitution, Kurdish L2 users exchanged $\langle\mathrm{e}\rangle$ for $\langle\mathrm{i}\rangle$ and vice versa, as in necissity (necessity), mercefull (merciful), diffeculties (difficulties), sensetive (sensitive), openion (opinion). Other vowel substitutions were as follows:

$\langle\mathrm{u}\rangle$ for $\langle\mathrm{o}\rangle \operatorname{sun}(\mathrm{son}),\langle\mathrm{o}\rangle$ for $\langle\mathrm{i}\rangle,\langle\mathrm{a}\rangle,\langle\mathrm{e}\rangle$ and $\langle\mathrm{u}\rangle$ posotive (positive), [tought (taught), becouse (because)(2)], liston (listen), absolote (absolute), $\langle\mathrm{a}\rangle$ for $\langle\mathrm{o}\rangle,\langle\mathrm{i}\rangle$ and $\langle\mathrm{e}\rangle$ mather (mother), socaety, sociaty (society), $\langle\mathrm{a}\rangle$ for $\langle\mathrm{u}\rangle$ and $\langle\mathrm{e}\rangle$ aneducated (uneducated), pears (peers), mannar (manner), $\langle\mathrm{e}\rangle$ for $<\mathrm{a}>$ and vice versa peper (paper), consequant (consequent).

As far as the consonant substitutions are concerned, the learners exchanged various pair of consonants as follows: 
$\langle\mathrm{c}\rangle$ for $\langle s\rangle$ and vice versa as in advice (n.) (advise) (v.)(4), vise versa (vice versa), nesseccery (necessary), $\langle\mathrm{s}\rangle$ for $\langle\mathrm{t}\rangle$ attension (attention), $\langle\mathrm{t}\rangle$ and $\langle\mathrm{s}\rangle$ for $\langle\mathrm{c}\rangle$ apprtiate, appretiating (appreciate), aprisiate, (appreciate), $\langle\mathrm{c}\rangle$ for $\langle\mathrm{t}\rangle$ essencial (essential), and finally $\langle\mathrm{f}\rangle$ for $\langle\mathrm{v}\rangle$ as in live (life) (2).

\section{Space Inaccuracies}

One of the common spelling inaccuracies in Kurdish L2 users' writing was found in separating the two parts of some closed compound words. The most common error was done with the compound word every thing (everything) (25) and can not (cannot)(11). Other space inaccuracy or word-split error were commonly identified in the following words:

some time (sometime)(3), some one (someone), some thing (something), any thing (anything), there for (therefor), may be (maybe), now adays (nowadays), what ever (whatever), them selves (themselves), other wise (otherwise).

\section{E. Capitalization}

Another common spelling inaccuracy identified in Kurdish L2 users' writing was the wrong use of capitalization rules of TL. The errors identified were as follows:

Them (them), Their (their), To (to), The (the), They (they), Learn (learn), Because (because), Passive (passive), All (all), Education (education), He (he)(6), Are (are), Nessesary (necessary), It s(2) (it’s)

\section{F. Transpositions}

Among the spelling errors, a few were identified to be classified as transposition. The pair of letters that was transposed frequently were $\langle\mathrm{e}\rangle$ and $\langle\mathrm{i}\rangle$. Examples of $\langle\mathrm{e}\rangle\langle\mathrm{i}\rangle$ transposition found in $\mathrm{L} 2$ users spelling errors were thier (15) (their), promenint (prominent), bigenning (beginning).

\section{G. Unique Types}

The last type of spelling errors in Kurdish L2 users' writings were different from the popular forms of spelling errors. These erroneous words cannot be classified under the above types of errors. The misspellings have various reasons behind them. For example, the misspelling found in childs (children) (3), activeless, unactive (inactive), feeled (felt), Theirselves (themselves), and sincerness (sincerity) was due to inappropriately projecting of regular plural forming of TL onto irregular words, adding suffixes to 
form a different part of speech and regular/irregular past form. Other errors occurred were unique to Kurdish EFL learners, they were as follows:

agenst (against), apportunty (opportunity), prepear, preppear (prepare), bcoz (because), desiar (desire), obosite (opposite), instaid (instead), feauter (future), there(3) (their), motatative (motivated), stragle (struggle), alots (lots of or a lot of), feature (future), fell (feel), their selves (themselves) (7).

\section{Discussion and Interpretation}

Various reasons contribute to make learners commit the spelling mistakes. One reason was the faulty generalization done by reaching an inductive generalization by the part of the learners without sufficient knowledge by which the generalized my not apply on irregular forms. To elaborate, in the following misspelt words of easser, easyer (easier), the source of the error is the writer's inductive generalization that when adding the comparative (er) for the word easy, the last consonant is doubled, however, the final (y) did not change to (i) then adding the suffix to the same word. The same is true with both childs (children) and dishs (dishes) as the writer thought that the regular pluralization rule is also applicable on the word child in case of the former and sufficient knowledge of L2 pluralization that making the noun dish plural needs -es not -s. It is then concluded that overemphasis on certain morphological rule may backfire and cause undesired results.

Another reason was that learners were influenced by their L1 writing system as it has a one to one letter sound/correspondence. For example, the way the word agenst (against) was written implies that the writer thought that the word is written in accordance to its transcription; /a'genst/, unlike its written form 'against'. The same is true with the errors desiar (desire), stragle (struggle) and prepear (prepare) for which the letter/sound correspondence, which is common in Kurdish writing system, was applied.

\section{Conclusion}

Based on the results obtained, the error types were interlingual, intralingual and unique. The results indicated that the errors were caused by various reasons; lack of mechanical knowledge of L2 writing, overgeneralization and lack of concentration. The reasons identified implies that they all have instructional background. First, it seems that the learners did not have knowledge of mechanics of L2 writing. Secondly, they did not have adequate knowledge of those mechanics which is usually gained by learners' exposure to sufficient practice exercises. Finally, the learners did not pay due attention to L2 writing in general and word spelling in particular because L2 writing has not been taken seriously as one of the four basic skills 
of language learning. All the above points imply that there is a pedagogical problem that entails serious reconsideration and examination. Hence, the results offer suggestions and recommendations for L2 language teachers, syllabus designers and stakeholders. They also present remedy for the problem. In conclusion, the types of spelling error in Kurdish EFL learners demands L2 teachers to have special remedial instructions and exercises to tackle the problem.

\section{References}

[1] K. N. Abdullah, “An Investigation of Students' Use of the Mechanics of Writing in English in Northern Iraq,” M. Arts thesis, Near East University, Nicosia, Cyprus, June 2015.

[2] I.A. Ahmed, "Different types of spelling errors made by Kurdish EFL learners and their potential causes.” International Journal of Kurdish Studies, vol. 3, no. 2, pp. 93 - 110, May 2017.

[3] K. M. Al-zuoud and M. K. Kabilan, “Investigating Jordanian EFL Students' Spelling Errors at Tertiary Level.” International Journal of Linguistics, vol. 5(3), pp. 164-176, 2013.

[4] E. M. Alhaisoni, K. M. Al-Zuoud and D. Ram Gaudel, "Analysis of spelling errors of beginner nearners of English in the English foreign language context in Saudi Arabia." English Language Teaching, vol. 8(3), pp.185-192, 2015.

[5] W. Bancha "What causes spelling errors of Thai EFL students?” ARECLS, Vol.10, pp. 107-129, 2013.

[6] V. Cook, Second language learning and language teaching (5 ${ }^{\text {th }}$ edition). New York: Taylor \& Francis, 2016.

[7] V. Cook, "L2 Users and English Spelling". Journal Multilingual and Multicultural Development, vol. 18, n. 6, pp. 474-88, 1997.

[8] M. Fender, "Spelling knowledge and reading development: Insights from Arab ESL learners." Reading in a Foreign Language, Vol. 20(1), pp. 19-42, 2008.

[9] M. Saeidi, \& M. R. Khodadust, "Spelling Errors of Iranian School-Level EFL Learners: Potential Sources.” The Journal of Applied Linguistics Vol. 3, Issue 1. pp. (188-207), 2010. 
[10] S. N. Subhi and M. S. M. Yasin, "Investigating Study of an English Spelling Errors: A Sample of Iraqi students in Malaysia.” International Journal of Education and Research, Vol. 3 No. 6 June 2015.

\footnotetext{
${ }^{1}$ Kurdish Language is from the Iranian branch of the Indo-European languages. It has around thirty million speakers distributed among the countries of Turkey, Syria, Iraq and Iran. The language has three major dialects of northern (Kurmanji), middle (Sorani) and southern (Hawrami). The second dialect, which is spoken in northern Iraq and western Iran, uses the modified Arabic script. The sorani dialect has a writing system which is alphabetic, sound based and a phonetic language, i.e., there are one two one correspondence between letters and phonemes.
} 